9 Stracciari A, Rebucci GG. Transient global amnesia and migraine: familial incidence. J Neurol Neurosurg Psychiatry 1986;49: 716-9.

10 Miller JW, Petersen RC. Transient global amnesia: clinical characteristics. Neurology 1984;34(suppl.1):244.

11 Fisher CM. Late life migraine accompaniments as a cause of unexplained transient ischemic attacks. Can J Neurol Sci 1980;7:9-17.

12 Feely MP, O'Hare J. Episodes of acute confusion or psychosis in familial hemiplegic migraine. Acta Neurol Scand 1982;65: 369-75.

13 Ziegler DK. Genetics of migraine. In: Vinken PJ, Bruyn GW, Klawans HL, eds. Handbook of Clinical Neurology, Amsterdam, Elsevier Science Publishers, 1986, Vol. 4 (48:23-30).

14 Lucas RN. Migraine in twins. J Psychosom Res 1977;20:147-56.

15 Olesen J. The pathophysiology of migraine. In Vinken PJ, Bruyn GW, Klawans HL, eds. Handbook of Clinical Neurology, Amsterdam, Elsevier Science Publishers, 1986, Vol. 4 (48:59-83).

16 Olesen J, Jörgensen MB. Leao's spreading depression in the hippocampus explains transient global amnesia. A hypothesis. Acta Neurol Scand 1986;73:219-20.

17 Caplan LB. Transient global amnesia. In: Vinken PJ, Bruyn GW, Klawans HL, eds. Handbook of Clinical Neurology, Amsterdam, Elsevier Science Publishers, 1985, Vol. 1 (45:205-18)

18 Hinge $H$, Jensen TS, Kjaer M, Morquardsen J, de Fine, Olivarius B. The prognosis of transient global amnesia. Results of a multicenter study. Arch Neurol 1986;43:673-6.

\section{Muscle histology of hypocalcaemic myopathy in hypoparathyroidism}

Sir: In addition to having the typical signs of idiopathic hypoparathyroidism, the patient described here showed features of hypocalcaemic myopathy, rarely reported previously in this condition. ${ }^{1-6}$

A 65 year old woman was admitted to hospital with complaints of intermittent carpopedal spasm (tetany) and easy fatigability. She had noted carpopedal spasm 20 years before. Five years before admission, she had had operations for bilateral cataracts. For the past year, she had had three drowsy attacks associated with vomiting and cold sweating, each of which lasted for 5 to 10 minutes. There was no past history or family history of neuromuscular disease.

On physical examination, the patient was normal in stature and appearance. She had varicose veins and ecchymoses on both legs. The skin was dry and not infected. Neurological examination revealed hoarseness, mild dysphagia and moderate weakness predominantly affecting the proximal limb muscles. Muscle stretch reflexes were diminished with hypotonicity. There was no sensory disturbance or incoordination. The WAIS score revealed a verbal IQ of 86 . A typical carpal spasm appeared 30 seconds after a blood pressure cuff was inflated. The Chvostek sign was present on both sides.

On laboratory findings, serum calcium was low $(5.0 \mathrm{mg} / \mathrm{dl})$ and phosphorous 7.0 $\mathrm{mg} / \mathrm{dl}$. Unfortunately serum myoglobin level was not measured. The parathyroid hormone (PTH) concentration, 0.18 ng$\mathrm{E} / \mathrm{ml}$, was less than normal. Reaction to exogenous PTH (Ellsworth-Howard test) was positive. Serum vitamin $D_{3}$ level was 12 $\mathrm{ng} / \mathrm{ml}$ (normal 14-42). The level of serum creatine kinase (CK) was high (756 IU/1, normal $<110$ ) with mild elevation of lactic dehydrogenase and aldolase activity. The MB isozyme of CK was $5 \%$ and MM $95 \%$. Electrocardiography showed a prolonged QTc of 0.58 second. Echocardiographic examination revealed cardiomyopathy and a pericardial effusion of $350 \mathrm{ml}$. Cranial computed tomography revealed bilateral symmetrical calcification of the basal ganglia and the dentate nuclei. Electroencephalography showed slowing of background activity without localising features. An electromyographic finding was an increase in polyphasic long-duration potentials in the distal part of the leg, but was normal in the proximal muscles. Motor nerve conduction velocities were normal

The muscle biopsy specimen was taken from the quadriceps femoris muscle. Lightmicroscopical examination revealed variety in fibre size without fibre necrosis, vacuole or inflammatory cell infiltration. Routine ATPase reaction showed type 2 fibre atrophy (fig a). Electron microscopical examination showed perinuclear accumulation of mitochondria and focal myofibrillar degeneration. A few muscle fibres had concentric laminated bodies. In addition to these exam- 으 inations, immunohistochemical localisation $Z$ of myoglobin was studied. The formalin- $\stackrel{\mathbb{D}}{\square}$ fixed paraffin-embedded 3- $\mu \mathrm{m}$-thick sections $\bar{O}$ were stained using anti-myoglobin rabbit $\stackrel{\varrho}{\complement}$ serum (1:200, DAKO, Denmark) by PAPc̄ method of Sternberger. ${ }^{7}$ In our patient, $\square$ negative immunoreaction for myoglobin ${ }^{\infty}$ was observed in some muscle fibres, many of $\frac{\widehat{\Omega}}{2}$. which correspond to atrophic type 2 fibres; positive reaction, on the contrary, was observed in the remaining fibres (fig b). In control patients with amyotrophic lateral sclerosis, almost all fibres, including atro- $\overline{0}$ phic type 2 fibres, were immunostained for $\frac{\mathrm{C}}{\mathrm{O}}$ myoglobin, though the intensity was varied. $\overline{\bar{D}}$ Normal muscle fibres of necropsied patients $\vec{D}$ without neuromuscular diseases were also $\varrho$ immunostained.

After administration of calcium and $1 \alpha$-hydroxyvitamin $D_{3}$, serum level of calcium and CK returned to normal values. $\vec{\omega}$ Tetany, muscle weakness, easy fatigability, $\stackrel{\omega}{\sigma}$ pericardial effusion and other symptoms and signs disappeared within 4 weeks.

The calcium ion plays many important 0 roles in neuromuscular function. In hype calcaemic patients, increased excitability of $\infty$ neuromuscular junction results in the we known manifestation of tetany, main 0 affecting the distal muscles. Howeve, several authors ${ }^{1-6}$ have noted other mati festations: proximal muscle weakness, easy fatigability and elevated muscle-associated enzymes, and designated them as hyp $\vec{\theta}$ calcaemic myopathy related to direct effect $\infty$ of hypocalcaemia on muscle fibres. Frame, $\rightarrow$. however, pointed out that the elevated serum enzyme levels could be related to the tetany. In our patient, tetany appeared only two or three times a day, lasting for a few seconds, and serum CK activity did not $\frac{0}{\mathrm{D}}$ fluctuate after the tetany of three minutes' $\varrho$ duration was induced by forearm ischaemia, $\overline{\bar{O}}$ suggesting that the tetany could be mini- 3 mally related to the high $\mathrm{CK}$ activity.

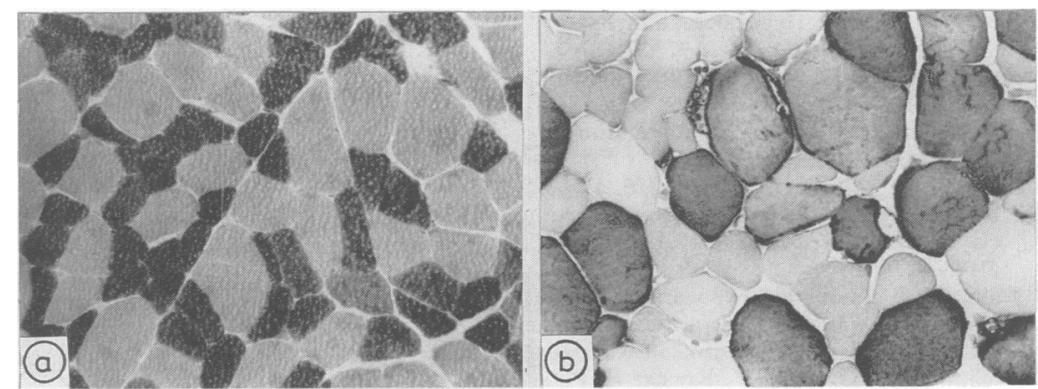

Fig Quadriceps femoris. (a) Routine ATPase stain, demonstrating type 2 fibre atrophy (cryostat section, $\times 150)$. (b) Immunostaining for myoglobin, demonstrating negative staining of atrophic fibres (paraffin section, $\times 300$ ). 
The morphological studies of muscle biopsy specimens have shown normal ${ }^{56}$ or non-specific changes ${ }^{1}$ in the reported cases. We studied immunohistochemical localisation of myoglobin in biopsied muscles. Myoglobin, a small molecule $(17,000$ daltons), is a soluble protein and is found abundantly in cardiac and skeletal muscles. Serum myoglobin increase with muscle cell damage, and it is a more sensitive indicator than CK activity. 9 Sidney $e t$ al $^{10}$ have shown using an indirect immunofluorescent technique that myoglobin disappears from cardiac muscle fibres and appears only in the interstitial spaces after $\mathbf{3 0}$ minutes of ligation of a coronary artery. Interestingly, immunohistochemical study of our case revealed that some muscle fibres, mainly small atrophic fibres, were negative for myoglobin stain in contrast with positive stain of the remaining fibres. This suggests that hypocalcaemia may lead to myoglobin leakage from skeletal muscles. With respect to the experimental data of Streffer et al, 11 who demonstrated the leakage of cellular enzymes in calcium-free media, Kruse et al $^{6}$ suggested that hypocalcaemia may lead to reversible alterations in enzyme contents of skeletal muscles without structural changes.

Finally, our findings indicate that hypocalcaemic myopathy is a distinct clinical entity.

HARUYASU YAMAGUCHI KOICHI OKAMOTO MIKIO SHOOJI MITSUNORI MORIMATSU SHUNSAKU HIRAI

Department of Neurology, Gunma University School of Medicine, Showamachi, Maebashi, Gunma, 371 Japan

\section{References}

1 Wolf SM, Lusk W. Hypocalcemic myopathy. Bull Los Angeles Neurol Soc 1972;37:167-77.

2 Hower J, Struck H, Tackmann W, Bohlmann H-G. Myopathy and elevated serum enzymes in a case of hypoparathyroidism. $Z$ Kinderheilk 1974;116:193-6.

3 Snowdon JA, Macfie AC, Pearce JB. Hypocalcaemic myopathy with paranoid psychosis. J Neurol Neurosurg Psychiatry 1976; 39:48-52.

4 Walters RO. Idiopathic hypoparathyroidism with extrapyramidal and myopathic features. Arch Dis Child 1979;54:236-8.

5 Piechowiak H, Grobner W, Kremer H, Pongratz D, Schaub J. Pseudohypopara thyroidism and hypocalcemic "myopathy". A case report. Klin Wochenschr 1981;59: 1195-9.
6 Kruse K, Scheunemann W, Baier W, Schaub J. Hypocalcemic myopathy in idiopathic hypoparathyroidism. Eur J Pediatr 1982;138: 280-2.

7 Sternberger LA. The unlabeled antibody enzyme method. In: Immunohistochemistry, 2nd ed. New York: Wiley \& Sons, 1979:129-71.

8 Frame B. Neuromuscular manifestations of parathyroid disease. In: Vinken PJ, Bruyn GW, eds. Metabolic and Deficiency Diseases of the Nervous System, part 1. Handbook of Clinical Neurology Vol 27. Amsterdam: North-Holland Pub 1976:283-320.

9 Askmark H, Osterman PO, Roxin LE, Venge P. Radioimmunoassay of serum myoglobin in neuromuscular diseases. J Neurol Neurosurg Psychiatry 1981;44:68-72.

10 Sidney PK. Diffusion of myoglobin in the diagnosis of early myocardial ischemia. Lab Invest 1982;46:265-70.

11 Streffer C, Williamson DH. The effect of calcium ions on the leakage of protein and enzymes from rat liver slices. Biochem $J$ 1965;95:552-60.

Diagnosis of juvenile-adult form of neuroaxonal dystrophy by electron microscopy of rectum and skin biopsy

Sir: Generalised neuroaxonal dystrophy (NAD) was originally described as the pathological hallmark of an infantile neurologic disorder which is characterised by delayed motor and speech development and combinations of dystonia, hypotonia or rigidity and spasticity, optic nerve involvement, and dementia. The disease is often familial. It terminates fatally toward the end of the first decade of life. ${ }^{1-4}$ It became obvious that late-onset forms of neuroaxonal dystrophy exist, which begin in late childhood or adolescence and present with a more or less protracted course. ${ }^{56}$

Whether these diseases are truly different nosologic entities from the disorder first described by Hallervorden and Spatz in $1922^{7}$ and bearing their names, is still a matter of debate. ${ }^{8}$ By neuropathological definition, Hallervorden-Spatz-syndrome is a localised form of neuroaxonal dystrophy with predilection of the disease process for the pallidum and substantia nigra, ${ }^{9}$ in which pathological pigment is accumulated. Though abnormal pigmentation is a pathognomic feature of Hallervorden-Spatzsyndrome, it has occasionally been observed also in other infantile forms of generalised neuroaxonal dystrophy. ${ }^{8}$
If the diagnosis is suspected during life, it should be ascertained by biopsy. In infantile $Z$ and late-infantile forms of neuroaxonal dys $-\frac{D}{C}$ trophy, brain biopsy, 4101112 may beo replaced by biopsy of tissue other than CNSE including peripheral nerve and motor endō plates, ${ }^{13-16}$ rectum, ${ }^{17,18}$ skin and conjunctiva ${ }^{19.20}$ and dental pulp. ${ }^{21}$ Much less information is available about late-onset? cases. A cortical brain biopsy established the diagnosis in a sporadic case of a young adult $\mathrm{K}$ with neuroaxonal dystrophy. ${ }^{22}$ We report a patient with juvenile-adult neuroaxonal $\stackrel{\bar{P}}{+}$ dystrophy, in whom electron microscopy ofo rectal and skin biopsies verified the diagno-음 sis.

A 32 year old Caucasian woman had an $\stackrel{\mathrm{D}}{\overparen{D}}$ unremarkable family history. She first developed signs of the disease at age 14 years, $\infty$ when she began to articulate poorly. At that $\vec{\circ}$ time her school performance was still high, but deteriorated, so that she graduated from $\vec{\omega}$ high school with low marks. She did less well in gymnastics and was reported to be "clumsy". At 23, her handwriting became poor, and first dystonic and athetoid pos- $-\mathrm{C}$ tures were observed. She was examined in this medical centre at age 31. Previous $\infty$ efforts had failed to provide a diagnosis. $\sqrt{\mathrm{g}} \mathrm{V}$ physical examination was normal. On ne్응 rological examination she had a severe dy? tonic and athetoid gait disorder but was sapl $\vec{c}$ able to walk unaided. Her speech was barety intelligible due to disturbed articulation and prosody. Athetoid movements were abse $\overrightarrow{0}$ at rest and when she was not tense but wri $\infty$ and fingers especially of the right hand. remained in a dystonic posture. Examination of the cranial nerves revealed abolished vertical and slowed horizontal optokinetic responses. Muscle stretch reflexes were normoactive on both sides. $\frac{\circ}{\not}$ Both plantar responses were flexor. Muscle tone of the limbs was slightly decreased. $\overrightarrow{2}$ Sensation was undisturbed. There were no 3 obvious cerebellar signs.

On psychological testing, memory impairment and dull affect were observed. Her performance IQ of 96 compared with the $\overline{\bar{\partial}}$ premorbid IQ of 136. There were signs of an organic syndrome on Benton visual $\frac{0}{3}$ retention and Raven SPM tests. Electroencephalography was normal. Computed of tomography and nuclear magnetic resonance imaging showed a width of the third 0 ventricle at the upper limit of normal but were otherwise unremarkable. There were $\frac{D}{0}$ no signs of peripheral nerve involvement as determined by electrodiagnosis and EMG. $N$ Visual and auditory evoked potentials revealed delayed latencies, and somato- $O$ sensory evoked potentials a slight reduction in amplitude of the early component. 